MENG MENG, Ph.D.

Corresponding Author

E-mail: mengm@ntu.edu.sg

1. TUM CRATE, 1 CREATE Way

\#10-02 CREATE Tower, Singapore 138602, Singapore

2. Centre for Infrastructure Systems,

School of Civil and Environmental Engineering

Nanyang Technological University

50 Nanyang Avenue N1-B1b-09, Singapore 639798, Singapore

ABDUL AHAD MEMON, Ph.D.

E-mail: ab_ahad@eim.ae

International Vision for Engineering Solutions (IVES),

Khalifa Bin Zayed

Street-Building No. C36, P.O Box 107894, Abu Dhabi,

United Arab Emirates

YIIK DIEW WONG, Ph.D.

E-mail: cydwong@ntu.edu.sg

Centre for Infrastructure Systems,

School of Civil and Environmental Engineering

Nanyang Technological University

50 Nanyang Avenue N1-B1b-09, Singapore 639798, Singapore

SOI HOI LAM, Ph.D.

E-mail: soihoi.lam@gmail.com

Transportation Infrastructure Office

Rua Dr. Pedro José Lobo, NO.1-3, Ed. Banco Luso

Internacional, Macao S.A.R. 999078, China
Intermodal Transport

Original Scientific Paper

Submitted: Oct. 16, 2014

Approved: Nov. 24, 2015

\title{
DYNAMIC INTERACTIONS BETWEEN COMMUTERS' MODE CHOICE BEHAVIOUR AND INTEGRATED TRAVELLER INFORMATION
}

\begin{abstract}
A commuter's mode choice decision in response to provided traveller information is directly dependent on the temporal and spatial interactions between the available trave modes, the network performance and control schemes, and the supplied traveller information. A self-developed simulation model - Intelligent Network Simulation Model (INSIM) - was employed to simulate travel scenarios in a multimodal transportation network. A set of experiments was designed to analyse and evaluate the influence of traffic information on commuter's mode choice, using a medium-sized area in Singapore. Simulation results showed that the private-to-public mode switch propensity bears a strong and direct relation with amount of disseminated integrated multimodal traveller information (IMTI) as well as timeliness of information update. Other influential factors include degrees of accessibility and compliance to IMTI, and congestion-related events such as accidents.
\end{abstract}

\section{KEY WORDS}

integrated multimodal traveller information; mode choice; traffic simulation; switch propensity;

\section{INTRODUCTION}

Travel mode choice behaviour, as referring to the manner travellers select their travel mode(s), is inherently influenced by travellers' (perceived) knowledge about travel conditions of available choices; this knowledge about travel conditions is collectively termed as traveller information. Timely provisions of strategic traveller information can contribute significantly in improving transport network efficiency while affording better transport services to commuters. Due to the limited real-world deployment of advanced multimodal traveller information system (AMTIS) infrastructure, and absence of substantial conceptual and theoretical frameworks to guide data collection, simulation-based approaches become an important tool to perform these investigations [1-4].

Numerous studies have been done to investigate the influence of AMTIS on mode choice behaviour through field survey and simulation analysis. The research findings have not reached a common conclusion. Whereas many publications reported AMTIS hav- 
ing a significant influence on mode choice behaviour [5-7], yet others found that AMTIS would not affect mode choice behaviour [8]. Traffic characteristics inherently vary across the cities encompassing different trip stages, different mix of travellers, as well as different travel information dissemination methods. Two well-known methods in the field survey are revealed preference (RP) and stated preference (SP). To analyse travellers' response to the traffic information, RP approach is based on real trip experience, while SP method is based on hypothetical scenarios. The major drawback of the field survey method is that it is time- and cost-consuming and the results are not repeatable for various situations. Simulation method can overcome the limitations of the field survey method. Once the parameters are calibrated well, the simulation model can be applied to forecast results for different objectives.

A number of simulation models have been designed specifically to explore the dynamic effects of information provision on network performance, such as INTEGRATION [9], THOREAU [10], DYNASMART [11], AIMSUN2 [12], and PARAMICS [13]. While all these simulation models have been successfully applied in particular studies, a common shortcoming is the relatively limited range of their applications. Some of them are designed for particular applications and are useful only for specific purposes, while others do not support the provision of integrated traveller information systems and transit operations. To date, no model has sufficient integrated componentry and functionality required for evaluation of dynamic control and route guidance strategies in a multimodal environment on surface street network [14-15].

The authors have developed an Intelligent Network Simulation Model (INSIM) in a previous study, which can realistically present complicated scenarios in which real-time multimodal traveller information is provided to commuters and network performance measures are recorded [16]. INSIM provides a flexible platform to dynamically analyse the performance of multimodal networks with a variety of elements that are subject to external uncertainties or correspond to system design parameters. Thus, the controlled interactive experiments conducted in a simulated environment are undertaken as reported in this paper. These experiments can provide the platform to analyse the commuters' mode choice behaviour under the influence of AMTIS. The designed approach provides a higher degree of experimental control, systematic investigation of network performance and its determinants, and a wide range of scenarios that are not practically available through observation.

The prime objectives of this paper are: 1) to analyse the significance of commuters' mode choice model in an intelligent transportation network simulation framework, 2) to quantify the impacts of various information provision strategies, and the traveller infor- mation update timing on commuters' mode switching propensity, and 3) to evaluate the influence of traveller information on the network level-of-service by incorporating certain changes in the transportation infrastructure/network. The previous study about the simulation model INSIM shall be briefly described in Section 2, while a detailed description of experiments is discussed in Section 3. The experimental results provide insight in the Intelligent Agent's (IA's) capabilities to simulate the effects of integrated multimodal traveller information on the commuters' mode choice behaviour. They also suggest guidelines for the AMTIS supply strategies with respect to information provision, and the transit operational schemes that could be effective in a multimodal network. A summary of the experiments and associated finding are documented in Section 4.

\section{INSIM MODEL}

An Intelligent Network Simulation Model (INSIM) has been developed by the authors in a previous study [16], which can analyse the impacts of different traveller information schemes on the travel behaviour of commuters who regularly use private mode of transport for their work/school trips. As shown in Figure 1, INSIM has four main components: INSIM expert system (IES), transportation network simulation model (PARAMICS), application programming interface (API), and data transfer interface (DTI). The IES is responsible for generating mode choice decision. The transportation network simulation model simulates the traffic and generates travel statistics as output files. These output text files are collected by the API, and transformed to Microsoft Access Database (MDB) files and exported to DTI, which is a database that stores the PARAMICS output files in MDB format while retaining intact the original time-dependent updated OD matrix file. The API takes in the information in the OD matrix file and releases the vehicles in the simulated network according to the pattern specified in the file.

The functionality of INSIM allows it to simulate traffic for every time stamp, and gather real-time traveller information on the available modes existing in the network. In this study, the simulated scenario imitates a multimodal transportation network, whereby integrated traveller information is being disseminated. INSIM dynamically generates OD matrix for each specified time stamp, relaxing a very common limitation of simulation models i.e. to simulate the travel demand based on the predetermined modal split. At the end of every time stamp the network simulation is paused till the new OD matrix for the commencing time stamp is generated. 


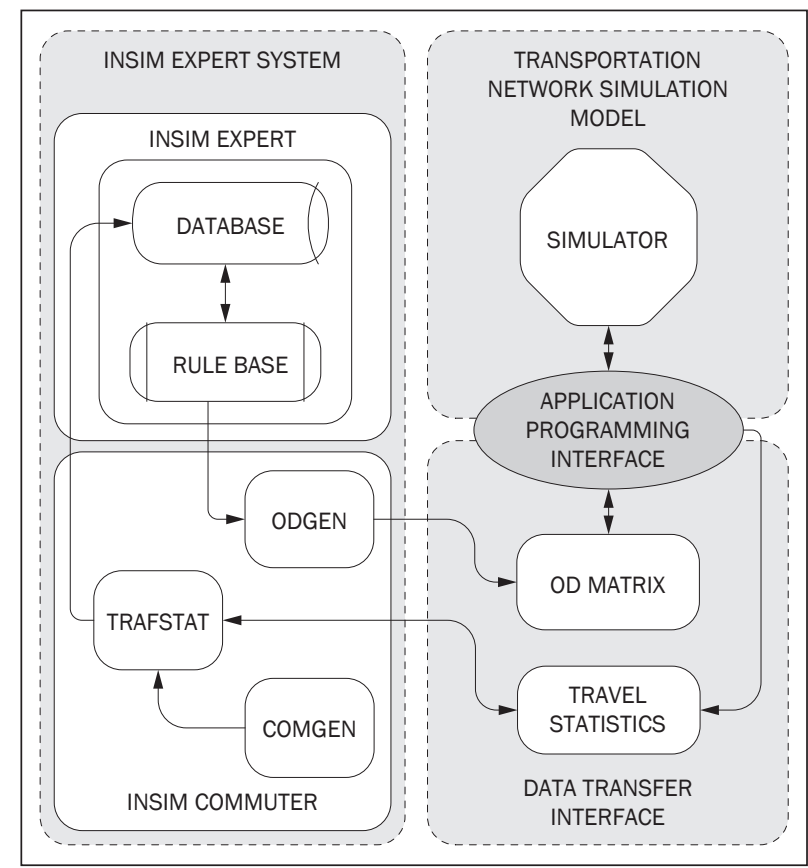

Figure 1 - Architectural Design of Intelligent Network Simulation Model (INSIM)

\section{EXPERIMENTAL DESIGN}

A set of experiments is designed to achieve the study objectives. In these experiments, the transportation network located in the central and western parts of Singapore is simulated. The simulated network covers the area bounded by 5 major expressways and a number of major arterials, as shown in Figure 2. Light Rail Transit (LRT) line does not exist in the real network, which was introduced here for illustration purpose.

Using the rule-based intelligent agent in INSIM, the commuters' mode choice behaviour is captured to analyse the effects of real-time multimodal traveller information on the performance of a multimodal transportation network. The commuters' mode decisions are usually dependent on their socio-economic characteristics and travel attributes. To understand the influence of socio-economic characteristics and travel attributes on individual's mode choice behaviour, a travel behaviour survey was conducted to calibrate INSIM's parameter.

After calibrating the INSIM model, the results of measures of effectiveness are segregated into two categories; the first category captures the overall network performance, and the second category is about the transit corridor. A total of 6 zones (zones 3, 8, 9, 10, 12 and 13) are classified as transit corridor, because in these zones the number of MRT stations is more than one, and the MRT stations are within the walking distance for most of the generated trips. The average travel time for the transit corridor trips is estimated for only the trips that originate and are destined within the transit corridor. All the other trips with one or both ends outside the transit corridor are considered as network-wide trips.

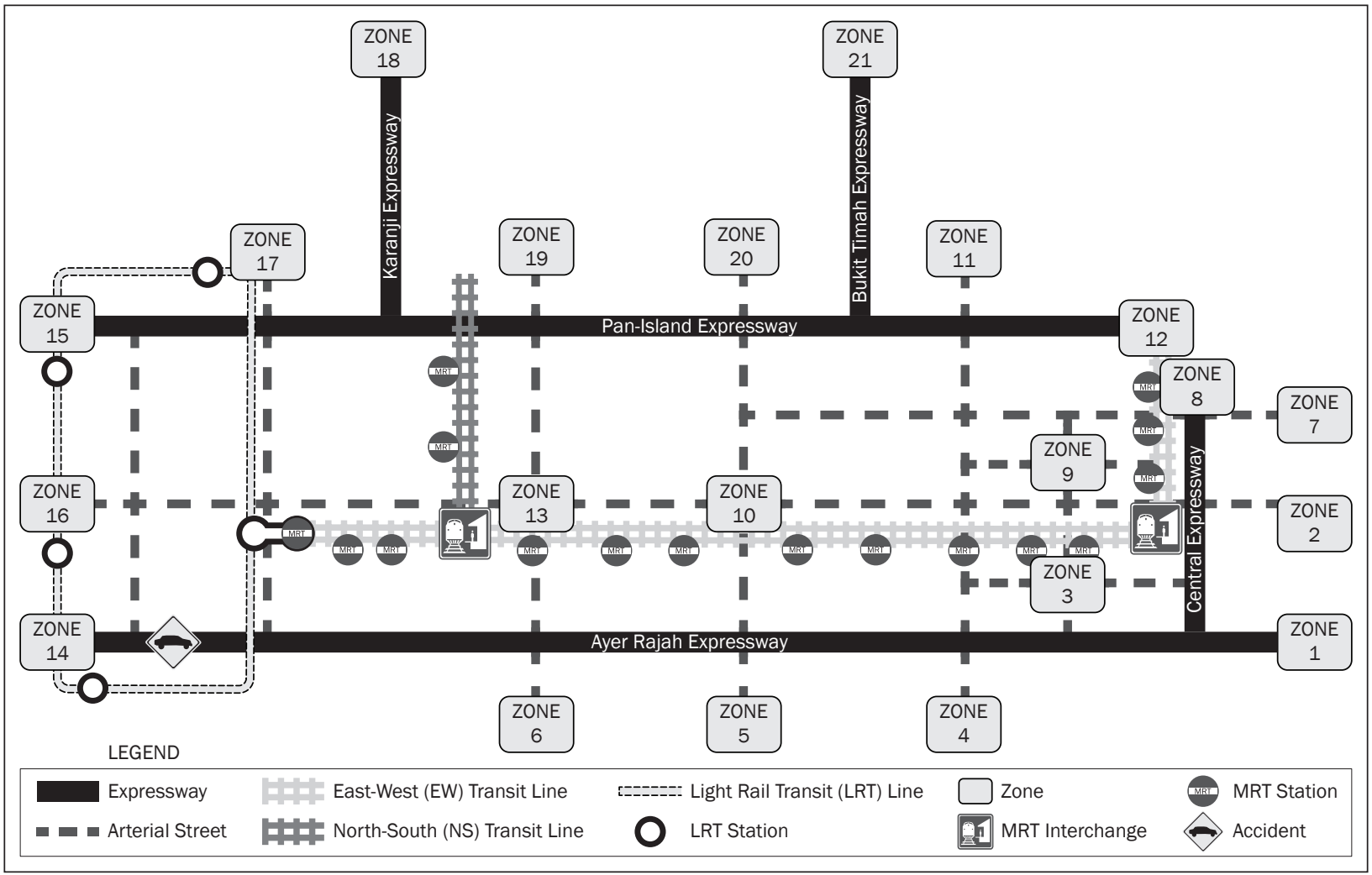

Figure 2 - Simulated Transportation Network 
The generated commuters can be assigned either public or private modes of transport. The simulator assigns private mode to those commuters who own a car. Thus, the congestion can be simulated based on the number of trips (commuters) being released in the network and their car ownership rate. The traffic survey was conducted to estimate the OD matrix for the study area. Based on the available travel demand statistics and the observed traffic counts, it was estimated that the total number of 79,877 trips were generated during the study period. The modal split of these trips was as follows: 33,120 (41.5\%) private mode trips, 41,887 (52.4\%) public mode trips, and 4,871 (6.1\%) non-motorised trips. During the simulation, only the motorised (i.e. public and private mode) trips were considered, such that a total number of 75,007 trips were generated, and 33,120 (44.2\%) trips were assigned private mode, whereas 41,887 (55.8\%) trips were assigned public mode of transport as their usual commute mode.

\section{EXPERIMENTAL SETUP AND RESULTS}

\subsection{First experiment - Base case}

Depending on the complexity of commuter's decision-making process, three different mode choice models have been developed. Each model is capable of predicting the commuter's mode choice based on socio-economic and travel characteristics. The IES has three different models to simulate the commuter's mode choice decision. These models are: Pure RuleBased Model (PRB), Discrete Choice Model (DCM) and Probabilistic Model (COM).

Results

Table 1 presents the results for the base case. The modal split and the performance measure are based on the situation where no traveller information is provided to the commuters. It can be observed that in the transit corridor the percentage of Massive Rapid Transit (MRT) trips is $18 \%$, which is higher as compared to that of the network-wide transit trips, i.e. $10 \%$. On the other hand, the network-wide Bus + MRT trips of around $41 \%$ are higher as compared to that of the transit corridor trips, which is $34 \%$. This can be due to the relatively better accessibility of MRT service in this transit corridor. The trip distribution of public and private modes remains similar in the transit corridor as well as throughout the network, with slight inclination towards public mode trips in transit corridor. By comparing the simulated average travel time by private mode i.e. 31.8 minutes with the estimated average travel time gathered from the previous travel behaviour survey [13] i.e. 31.1 minutes, it can be concluded that the simulated travel environment is consistent with the existing travelling condition of the study network.
Table 1 - Modal split and measures of effectiveness for base case scenario

\begin{tabular}{||l|l|l||}
\hline \hline Modal Split & $\begin{array}{l}\text { Network } \\
\text { Wide (NW \%) }\end{array}$ & $\begin{array}{l}\text { Transit } \\
\text { Corridor (TC \%) }\end{array}$ \\
\hline \hline Car & 44.2 & 43.92 \\
\hline Bus & 5.1 & 4.15 \\
\hline MRT & 10.1 & 18.01 \\
\hline Bus + MRT & 40.6 & 33.75 \\
\hline Total & 100 & 100 \\
\hline Public Mode & 55.8 & 56.08 \\
\hline Private Mode & 44.2 & 43.92 \\
\hline \hline Measures of Effectiveness & 38.8 \\
\hline \hline $\begin{array}{l}\text { Average Travel Time } \\
\text { by Private Mode (min) }\end{array}$ & 31.8 & 18.9 \\
\hline $\begin{array}{l}\text { Average Travel Time } \\
\text { by Public Mode (min) }\end{array}$ & 32.3 & 3.7 \\
\hline $\begin{array}{l}\text { Average Transit } \\
\text { Waiting Time (min) }\end{array}$ & 5.4 & \\
\hline $\begin{array}{l}\text { Average Travelling Speed } \\
\text { by Private Mode (kph) }\end{array}$ & 49.2 & \\
\hline $\begin{array}{l}\text { Average Travelling Speed } \\
\text { by Public Mode (kph) }\end{array}$ & 15.8 & \\
\hline $\begin{array}{l}\text { Average Trip Length } \\
\text { by Private Mode (km) }\end{array}$ & 26.1 & \\
\hline $\begin{array}{l}\text { Average Trip Length } \\
\text { by Public Mode (km) }\end{array}$ & 8.5 & \\
\hline \hline
\end{tabular}

\subsection{Second experiment -traveller information dissemination schemes}

In the second set of experiments the impacts of various schemes of disseminating traveller information were studied. Commuters are assumed to choose their modes of travel under the influence of traveller information. Four different scenarios as listed in Table 2 were simulated and the amount of information provided to the commuters was increased successively. Results

As shown in Table 2, the increase in the amount of provided traveller information increases the mode switching propensity in commuters when compared with the base case.

The maximum amount of information was provided in Scenario 4 resulting in maximum mode switching of around 20\%, whereas in Scenario 1, which has the minimum amount of information provided, the minimum mode switching of $15 \%$ was observed. The information provided in Scenarios 2 and 3 regard the transit level of comfort i.e. seat availability and number of transfers, respectively. It can be observed that such information can influence the commuters mode switching behaviour but with a mild effect. In the case of Scenario 2, the mode switching percentage increases by $2 \%$ as compared to Scenario 1 . But it further 
M. Meng et al.: Dynamic Interactions Between Commuters' Mode Choice Behaviour and Integrated Traveller Information

Table 2 - Effects of different schemes of traveller information on modal split and network performance

\begin{tabular}{|c|c|c|c|c|c|c|c|c|}
\hline \multirow[b]{4}{*}{ Modal Split (\%) } & \multicolumn{8}{|c|}{ Level of traveller information provided } \\
\hline & \multicolumn{2}{|c|}{ Scenario 1} & \multicolumn{2}{|c|}{ Scenario 2} & \multicolumn{2}{|c|}{ Scenario 3} & \multicolumn{2}{|c|}{ Scenario 4} \\
\hline & \multicolumn{2}{|c|}{$\begin{array}{l}\text { Travel Time, Travel } \\
\text { Cost, Waiting Time }\end{array}$} & \multicolumn{2}{|c|}{$\begin{array}{l}\text { Scenario } 1+ \\
\text { Seat Av. }\end{array}$} & \multicolumn{2}{|c|}{$\begin{array}{l}\text { Scenario } 2+ \\
\text { Transfer }\end{array}$} & \multicolumn{2}{|c|}{$\begin{array}{l}\text { Scenario } 3+ \\
\text { Access Time }\end{array}$} \\
\hline & NW (\%) & $\mathrm{TC}(\%)$ & NW (\%) & TC (\%) & NW (\%) & TC (\%) & NW (\%) & TC $(\%)$ \\
\hline Car & 37.4 & 34.3 & 36.6 & 32.9 & 36.4 & 32.4 & 35.4 & 31.3 \\
\hline Bus & 5.8 & 4.5 & 5.7 & 4.4 & 5.7 & 4.4 & 5.8 & 4.5 \\
\hline MRT & 14.1 & 24.9 & 14.8 & 26.1 & 14.8 & 26.2 & 14.9 & 26.3 \\
\hline Bus + MRT & 42.7 & 36.3 & 43 & 36.6 & 43.1 & 36.9 & 44 & 37.9 \\
\hline Total & 100 & 100 & 100 & 100 & 100 & 100 & 100 & 100 \\
\hline Public Mode & 62.6 & 65.7 & 63.4 & 67.1 & 63.6 & 67.6 & 64.6 & 68.7 \\
\hline Private Mode & 37.4 & 34.3 & 36.6 & 32.9 & 36.4 & 32.4 & 35.4 & 31.3 \\
\hline \begin{tabular}{|l} 
Mode Switching \\
(as compared to Base Case)
\end{tabular} & 15.3 & & 17.2 & & 17.6 & & 19.9 & \\
\hline Performance Measure & NW & TC & NW & TC & NW & TC & NW & TC \\
\hline Av. Travel Time - PrM (min) & 19.4 & 29.4 & 16.4 & 24.2 & 16 & 23.2 & 15.1 & 21.3 \\
\hline Av. Travel Time - PbM (min) & 26 & 27.2 & 22.9 & 20.2 & 22.7 & 20.1 & 22.2 & 20.5 \\
\hline Av. Transit Waiting Time (min) & 3.8 & 2.8 & 3.5 & 2.8 & 3.2 & 2.7 & 3.2 & 2.5 \\
\hline Av. Travelling Speed - PrM (kph) & 51 & & 51.5 & & 51.8 & & 52.4 & \\
\hline Av. Travel Speed - PbM (kph) & 18.9 & & 21.3 & & 21.5 & & 25.8 & \\
\hline Av. Trip Length - PrM (km) & 16.6 & & 14.2 & & 13.8 & & 13 & \\
\hline Av. Trip Length - PbM (km) & 8.2 & & 8.1 & & 8.1 & & 9.5 & \\
\hline
\end{tabular}

increases only by $0.4 \%$ in Scenario 3 as compared to that in Scenario 2. The information regarding the transit access time in Scenario 4 increases the transit ridership specifically in the transit corridor. In Scenario 3 , the percentage of trips taking MRT is $26 \%$, which increases by about $2 \%$ in Scenario 4 . The percentage of trips taking Bus + MRT increases from 37\% to 38\% between Scenarios 3 to 4, respectively.

\subsection{Third experiment - traveller information dissemination schemes}

To evaluate the impact of different information update time intervals, four scenarios were simulated where the information was fully provided to the traveller. In each scenario the information update time interval was changed, and its impact on the average vehicle travel time by private mode was observed. The update frequencies were varied to every 1 minute, 5 minutes, 10 minutes, and 15 minutes, respectively. Results

It can be observed from Figure 3 that for the 1-minute update time the average travel time by private mode does not show any fluctuation - after the simulation warm-up period of 20 minutes. It also shows a consistent average vehicle travel time of 15 minutes, which means that the simulation has achieved a steady state. While observing the 5-minute update time, it can be seen that the simulation also achieved a steady state after the warm-up period of 20 minutes, but a cyclic pattern is observed in each 5-minute update time interval. For example, at the beginning of $20^{\text {th }}$ simulation minute the average travel time goes on increasing till the $25^{\text {th }}$ simulation minute, and then again it goes on decreasing till $30^{\text {th }}$ simulation minute. This cyclic trend continues throughout the simulation period.

A similar kind of cyclic pattern can also be observed while analysing the 10- or 15-minute update timings. The reason for such cyclic behaviour can be the length of update time interval. In the case of 5-minute update time interval, the information disseminated at $20^{\text {th }}$ minute provides the details that the average travel

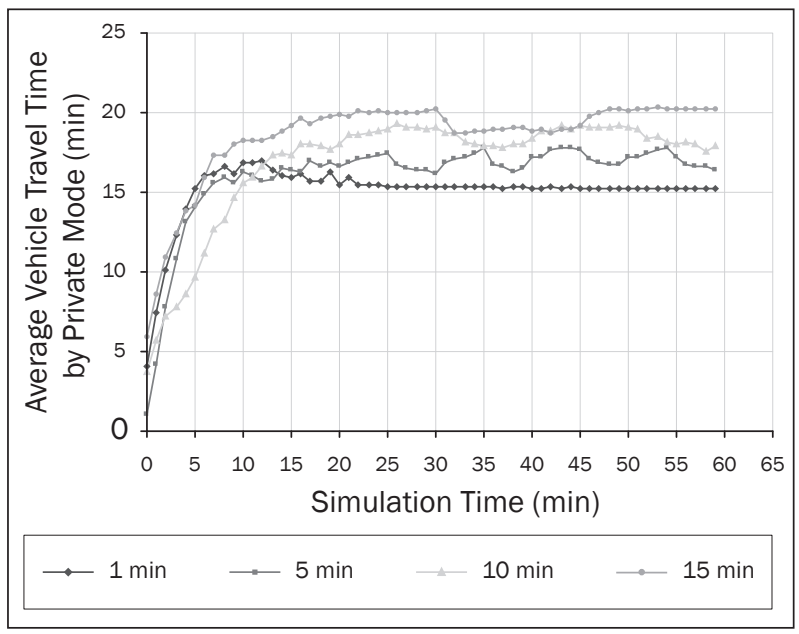

Figure 3 - Impact of information update time interval on average vehicle travel time by private mode 
time on the surface street network is lower. It means that there is less congestion in the network. This same information is provided in the $21^{\text {st }}$ minute, $22^{\text {nd }}$ minute, $23^{\text {rd }}$ minute, and $24^{\text {th }}$ minute, as the information is only updated in the $25^{\text {th }}$ minute. The commuters react accordingly and keep on taking the private mode as the system shows no or less congestion, whereas in reality the congestion is increasing every minute.

At the beginning of the $25^{\text {th }}$ minute the information is updated, and the system shows increase in travel time (i.e. occurrence of congestion). The commuters again react to such information with some shifting to public mode of transport. Thus, the number of private mode users keeps decreasing and the average travel time reduces till the $30^{\text {th }}$ minute, at which time the information is updated again and the system disseminates information that the network is not congested, which results in mode switching from public to private mode for the next 5 minutes. This cycle is repeated after every 5 minute's interval throughout the simulation period.

\subsection{Fourth experiment - access to traveller information}

Three different scenarios are simulated, such that in the first scenario $25 \%$, second scenario $50 \%$, and third scenario $75 \%$ of commuters have access to traveller information. The network travel environment and commuter characteristics are the same as in the base case. The commuters are provided with full information, and 1-minute time period is set as the update time interval for traveller information. All the commuters who received traveller information are assumed to comply with the provided information.

\section{Results}

It can be seen in Table 3 that greater access results in the largest effect on higher mode switching, and the overall network performance also improves. The highest mode switching and improvement in the network performance can be seen when $50 \%$ and $75 \%$ commuters have access to traveller information. When $25 \%$ or $100 \%$ of commuters have access to traveller information, the incremental improvement of the network performance measures or mode switching is relatively mild.

Considering the rate of change in commuters' mode switching or average travel time by private mode, it can be observed that the maximum rate of change ranges between $25 \%$ and $75 \%$. It shows that substantial network-wide improvements can be achieved when $75 \%$ commuters have access to traveller information. Further increment may result in some further changes in mode switching or improvement to the network performance measures.

\subsection{Fifth experiment - compliance with traveller information}

The impact of commuters' level of compliance with the traveller information is studied by simulating four different cases in which different percentages of commuters are assumed to comply with the provided information. Three experimental scenarios are simulated, such that in each scenario $50 \%, 75 \%$, and $100 \%$ of commuters are assumed to comply with the provided traveller information, respectively. The commuters who do not have access to information or do not comply with information are assumed to take their usual modes of travel. The network environment and

Table 3 - Impact of percentage of commuters having access to traveller information on modal split and network performance

\begin{tabular}{|c|c|c|c|c|c|}
\hline \multirow[b]{2}{*}{ Modal Split (\%) } & \multicolumn{5}{|c|}{ Percentage of Commuters having Access to Traveller information } \\
\hline & $0 \%$ & $25 \%$ & $50 \%$ & $75 \%$ & $100 \%$ \\
\hline Car & 44.2 & 42.7 & 39.7 & 37.3 & 35.4 \\
\hline Bus & 5.1 & 5.4 & 5.6 & 5.7 & 5.8 \\
\hline MRT & 10.1 & 11.3 & 12.5 & 13.7 & 14.9 \\
\hline Bus + MRT & 40.6 & 40.6 & 42.2 & 43.3 & 44 \\
\hline Total & 100 & 100 & 100 & 100 & 100 \\
\hline Public Mode & 55.8 & 57.3 & 60.3 & 63.6 & 64.6 \\
\hline Private Mode & 44.2 & 42.7 & 39.7 & 36.4 & 35.4 \\
\hline Mode Switching (as compared to base case) & 0 & 2.7 & 9.4 & 17 & 19.9 \\
\hline \multicolumn{6}{|l|}{ Performance Measure } \\
\hline Av. Travel Time - PrM (min) & 31.8 & 19.5 & 18.8 & 16.1 & 15.1 \\
\hline Av. Travel Time - PbM (min) & 32.3 & 22.9 & 22.8 & 22.3 & 22.2 \\
\hline Av. Travelling Speed - PrM (kph) & 49.2 & 49.9 & 49.9 & 51.2 & 51.8 \\
\hline Av. Travelling Speed - PbM (kph) & 15.8 & 18.9 & 21.3 & 23.5 & 25.8 \\
\hline Av. Transit Waiting Time (min) & 5.4 & 5.2 & 4.3 & 3.6 & 3.2 \\
\hline
\end{tabular}


M. Meng et al.: Dynamic Interactions Between Commuters' Mode Choice Behaviour and Integrated Traveller Information

Table 4 - Effects of commuters level of compliance with the traveller information on modal split and network performance

\begin{tabular}{||l|l|l|l|l||}
\hline & \multicolumn{3}{|l|}{ Percentage of Commuters Complying with the Traveller information } \\
\hline Modal Split (\%) & $0 \%$ & $50 \%$ & $75 \%$ & $100 \%$ \\
\hline \hline Car & 44.2 & 39.1 & 38.5 & 37.4 \\
\hline Bus & 5.1 & 5.5 & 5.7 & 5.7 \\
\hline MRT & 10.1 & 12.9 & 13.1 & 13.7 \\
\hline Bus + MRT & 40.6 & 42.5 & 42.8 & 43.2 \\
\hline Total & 100 & 100 & 100 & 100 \\
\hline Public Mode & 55.8 & 60.9 & 61.5 & 62.6 \\
\hline Private Mode & 44.2 & 39.1 & 38.5 & 37.4 \\
\hline Mode Switching (as compared to base case) & 0 & 10.3 & 13.3 & 16.8 \\
\hline \hline Performance Measure & & & & \\
\hline \hline Av. Travel Time - PrM (min) & 31.8 & 19.8 & 18.2 & 17.4 \\
\hline Av. Travel Time - PbM (min) & 32.3 & 23 & 22.9 & 22.5 \\
\hline Av. Travelling Speed - PrM (kph) & 49.2 & 49.7 & 50.1 & 50.5 \\
\hline Av. Travelling Speed - PbM (kph) & 15.8 & 19.2 & 22.4 & 25.4 \\
\hline Av. Transit Waiting Time (min) & 5.4 & 4.5 & 4 & 3.6 \\
\hline
\end{tabular}

commuter characteristics are the same as in the base case. The commuters are provided with full information, and 1-minute time period is set as the update time for traveller information. In all the scenarios only $75 \%$ of commuters are provided access to traveller information.

\section{Results}

As shown in Table 4, the increasing level of compliance increases mode switching and improves the overall network performance. As compared to the impact of access to traveller information, the level of compliance has more substantial influence on mode switching, and the overall network performance. It shows a consistent increase in mode switching and in the same manner a consistent decrease in average travel time by private mode. The commuters' access to traveller information and their level of compliance are interdependent. If the access rate is high and the level of compliance is low or vice versa, then in that case the improvement in network performance will not be significant. Thus, to achieve greater improvement it is necessary that a certain number of commuters may have access to, and comply with the provided traveller information. It can be concluded from the simulation results presented in Tables 3 and 4 that, if $75 \%$ of the commuters have access to traveller information all commuters should comply with the provided information to achieve significant network improvement.

Table 5 - Impact of feeder bus frequency on the modal split and overall network performance

\begin{tabular}{|c|c|c|c|c|c|c|}
\hline \multirow[b]{3}{*}{ Modal Split (\%) } & \multicolumn{6}{|c|}{ Feeder Bus Frequency } \\
\hline & \multicolumn{2}{|c|}{3 minutes } & \multicolumn{2}{|c|}{5 minutes } & \multicolumn{2}{|c|}{10 minutes } \\
\hline & NW & $\mathrm{TC}$ & NW & TC & NW & $\mathrm{TC}$ \\
\hline Car & 34.9 & 30.4 & 35.4 & 31.3 & 35.9 & 31.8 \\
\hline Bus & 5.8 & 4.5 & 5.8 & 4.5 & 5.7 & 4.5 \\
\hline MRT & 15.1 & 26.8 & 14.9 & 26.3 & 14.7 & 26 \\
\hline Bus + MRT & 44.2 & 38.4 & 44 & 37.9 & 43.7 & 37.7 \\
\hline Total & 100 & 100 & 100 & 100 & 100 & 100 \\
\hline Public Mode & 65.1 & 69.6 & 64.6 & 68.7 & 64.1 & 68.2 \\
\hline Private Mode & 34.9 & 30.4 & 35.4 & 31.3 & 35.9 & 31.8 \\
\hline Mode Switching (as compared to Base Case) & 20.3 & & 19.9 & & 18.1 & \\
\hline \multicolumn{7}{|l|}{ Performance Measures } \\
\hline Av. Travel Time - PrM (min) & 15.3 & 21 & 15.1 & 21.3 & 19.3 & 27.6 \\
\hline Av. Travel Time - PbM (min) & 21 & 19.1 & 22.2 & 20.5 & 23.2 & 20.5 \\
\hline Av. Travelling Speed - PrM (kph) & 2.5 & 2.4 & 3.2 & 2.5 & 4.9 & 4.5 \\
\hline Av. Travelling Speed - PbM (kph) & 52.6 & & 51.8 & & 51.9 & \\
\hline Av. Transit Waiting Time (min) & 25.8 & & 25.8 & & 25.3 & \\
\hline
\end{tabular}




\subsection{Sixth experiment - feeder bus frequency}

This set of experiments examines the effect of transit level of service on modal split and the resulting overall network performance. The experimental factor under consideration is the feeder bus service frequency. The network performance is compared under three different scenarios, such that for each respective scenario the bus frequency is varied to 3 minutes, 5 minutes, and 10 minutes. These frequencies result in 20 buses/hour, 12 buses/hour, and 6 buses/hour, respectively. These frequencies are assumed to be the same for all the feeder bus services. All the commuters are provided with complete information which is updated every minute. The commuters' level of compliance is set to $100 \%$, and $75 \%$ of commuters are given access to traveller information. The improvement in access time to MRT stations may enhance the transit ridership, and many private mode users may switch to public mode of transport.

Results

The impact of feeder bus frequency on the modal split and overall network performance is shown in Table 5, which shows a slight increase in the transit share with the increase in the bus frequency. For example, doubling the service frequency, i.e. from 6 buses/hour to 12 buses/hour, increases the public mode share by $1 \%$ throughout the network. However, improving the transit service encourages many private mode users to use transit mode.

The average waiting time within the transit corridor is decreased by about 2 minutes, and throughout the network, average travel time by public mode is decreased by 1 minute. The increase in the bus frequency to 20 buses/hour, does not lead to a significant change in the transit share but some savings in the average passenger waiting and travel time are observed.

\subsection{Seventh experiment - introduction of LRT service}

The effect of introducing a new Light Rapid Transit (LRT) service is considered in this experiment. The LRT line shown in Figure 2 is introduced and it connects zones $14,15,16$, and 17 with the main MRT station. The service frequency of LRT is assumed to be 5 minutes. The LRT operates at a flat fare of S\$1 per trip. Along with LRT the existing feeder bus services are also maintained. The network environment and commuter characteristics are the same as in the base case. The commuters are provided with full information, with 1-minute update time period, and $75 \%$ of commuters are provided access to traveller information, with $100 \%$ compliance level.

Results

The comparative statistics with and without the provision of LRT service are shown in Table 6, which can be observed that with the provision of LRT service the overall network performance is improved. In the transit corridor, the average travelling time by private mode and public mode is reduced by $3 \%$ and $8 \%$, respectively. The average travelling speed by public mode of transport is increased by $13.6 \%$, and network wide the average transit waiting time is reduced by $22 \%$. It can be also observed that the transit ridership and public mode share are influenced by the provision of LRT service. The overall mode switching is increased by $11 \%$. Specifically in the LRT service area (i.e. zones 14, 15, 16, and 17) 18\% of mode switching is observed. The LRT takes about $2 \%$ ridership out of the $6 \%$ of total bus share.

Table 6 - Comparative statistics with and without the provision of LRT service

\begin{tabular}{|c|c|c|c|c|}
\hline \multirow{3}{*}{ Modal Split (\%) } & \multicolumn{4}{|c|}{ LRT Service } \\
\hline & \multicolumn{2}{|l|}{ Available } & \multicolumn{2}{|c|}{ Not Available } \\
\hline & NW & TC & NW & TC \\
\hline Car & 34.1 & 31.2 & 35.4 & 31.3 \\
\hline Bus (LRT) & $4.2(1.8)$ & 4.5 & 5.8 & 4.5 \\
\hline MRT & 14.6 & 25.9 & 14.9 & 26.3 \\
\hline Bus + MRT & 45.2 & 38.5 & 44 & 37.9 \\
\hline Total & 100 & 100 & 100 & 100 \\
\hline Public Mode & 65.9 & 68.8 & 64.6 & 68.7 \\
\hline Private Mode & 34.1 & 31.2 & 35.4 & 31.3 \\
\hline Mode Switching (as compared to Base Case) & 22.1 & & 19.9 & \\
\hline Mode Switching in Zones 14, 15, 16, and 17 & 17.6 & & & \\
\hline \multicolumn{5}{|l|}{ Performance Measures } \\
\hline Av. Travel Time - Private Mode (min) & 14.8 & 20.6 & 15.1 & 21.3 \\
\hline Av. Travel Time - Public Mode (min) & 21.1 & 18.5 & 22.2 & 20.5 \\
\hline Av. Transit Waiting Time (min) & 2.5 & 2.4 & 3.2 & 2.5 \\
\hline Av. Travelling Speed - Private Mode (kph) & 53.2 & & 51.8 & \\
\hline Av. Travelling Speed - Public Mode (kph) & 29.3 & & 25.8 & \\
\hline
\end{tabular}




\subsection{Eighth experiment - incident management}

In this experiment the impact of traveller information is observed under the influence of congestion due to an accident. The scenario is simulated such that the accident is created on a section on the Ayer Rajah Expressway (AYE). As result, one lane is closed for a 100-metre length within the incident area for the entire simulation period. The lane capacity is reduced which results in congestion and increase in travel time on the specific expressway. The nearest zone to the accident location is zone 14, from which the trips generated are assumed to be directly affected. The network environment and commuter characteristics are the same as in the base case. The commuters are provided with full information that is updated after every minute, and $75 \%$ of them have access to traveller information, and all the commuters having access to traveller information shows $100 \%$ compliance with the provided information. The LRT and feeder bus services are also simulated as discussed in the seventh experiment.

Results

The comparative statistics regarding the modal split and the overall network performance are shown in Table 7, from which the impact of disseminating traveller information regarding the occurrence of the accident and the corresponding travel environment can be studied. It can be observed from Table 7 that the mode switching increases from $20 \%$ to $23 \%$ (i.e. $3 \%$ increase), while the average travel time by private mode increases by $105 \%$.

It is a clear indication that mode switching does not take place due to the increase in average travel time by private mode or due to the congestion factor, but rather it is due to the information about the accident and the corresponding delay on the specific expressway. The reasons are that this mode switching is not in proportion with the increase in the average travel time by private mode, because the average travel time by private mode increases by $105 \%$, whereas the mode switching does not change proportionally. Secondly, even though the mode switching occurring in the affected zone 14 is $16 \%$, there is no improvement in the average travelling speed by private mode on AYE, which is directly associated with zone 14 . The average travelling speed by private mode on AYE is $21.9 \mathrm{kph}$. It means that congestion prevails in the network, which is due to the impact of the accident that occurred on AYE, and it has resulted in the reduction of the expressway capacity.

\section{DISCUSSION}

Dynamic interactions between commuters' mode choice and the integrated traveller information are examined in this study based on a set of experiments. A simulation model was adopted to simulate the commuters' mode choice behaviour. Compared with the basic experiment, it was observed from the second set of experiments that the mode choice model can be used to study the impacts on the amount of information being provided and acted upon. Similarly, from the third set of experiments it was concluded that the information update time also influences the mode choice model. The mode choice model simulates the mode choice behaviour based on the provided information, rather than the changes occurring in the network. If the infor-

Table 7 - Comparative statistics with and without the accident

\begin{tabular}{|c|c|c|}
\hline \multirow{2}{*}{ Modal Split (\%) } & \multicolumn{2}{|l|}{ Scenario } \\
\hline & With Accident & Without Accident \\
\hline Car & 33.7 & 35.4 \\
\hline Bus (LRT) & 5.9 & 5.8 \\
\hline MRT & 14.7 & 14.9 \\
\hline Bus + MRT & 45.8 & 44 \\
\hline Total & 100 & 100 \\
\hline Public Mode & 66.3 & 64.6 \\
\hline Private Mode & 33.7 & 35.4 \\
\hline Mode Switching (as compared to base case) & 23 & 19.9 \\
\hline Mode Switching in affected zones 14 only & 16.5 & \\
\hline \multicolumn{3}{|l|}{ Performance Measures } \\
\hline Av. Travel Time - Private Mode (min) & 31 & 15.1 \\
\hline Av. Travel Time - Public Mode (min) & 22.1 & 22.2 \\
\hline Av. Transit Waiting Time (min) & 2.5 & 3.2 \\
\hline Av. Travelling Speed - Private Mode (kph) & 48.9 & 51.8 \\
\hline Av. Travelling Speed - Public Mode (kph) & 24.2 & 25.8 \\
\hline Av. Travelling Speed - Private Mode (kph) on AYE & 21.9 & \\
\hline
\end{tabular}


mation is updated within a shorter time interval, e.g. 1 minute, or longer interval, e.g. 15 minutes, the mode choice model would react accordingly.

The impact of traveller information on commuters' mode switching propensity was also analysed in the second experiment. It was found that the increase in the amount of integrated traveller information could enhance the commuters' mode switching propensity. Furthermore, it was also observed from this set of experiments that information on travel time, travel cost, and waiting time is more effective as compared to the information regarding the level of comfort. The information on transit level of comfort influences the commuters' mode choice, but the information on seat availability and access time is more effective than the information on the number of transfers.

The results obtained from the experiments conducted to analyse the accessibility and level of compliance with the provided traveller information provide knowledge about the percentage of commuters having access to the traveller information. Such knowledge can help the traveller information providers to estimate the optimum target population of commuters (market share) who may have access to the traveller information. It was found from this set of experiments that if $75 \%$ of commuter population has access to traveller information, and $100 \%$ of this population complies with the provided information, then significant improvement in the network wide performance measure can be accrued. Further increase in the proportion of commuters' access to traveller information may not yield significant further improvements.

The transit operational aspect was studied in the sixth and seventh experiments. It was observed that increasing the feeder bus frequencies or introducing LRT service can also improve the transit ridership. Better network-wide performance was observed when LRT service was introduced. It was found that commuters may like to travel in LRT to have access to MRT station as it provides less access time, and there is seamless integration with MRT service.

Lastly, the influence of traveller information in mitigating congestion and incident management was evaluated in the eighth experiment. It was found that disseminating traveller information does influence the mode choice behaviour. The commuters change their mode of travel from private to public, specifically in the zone that is directly affected due to the accident. It could not be established that any network wide improvement in the travel environment can take place as result of the dissemination of such traveller information.

\section{CONCLUSIONS}

This paper studied the mode choice behaviour under the influence of traffic information by a set of experiments. A self-developed simulation model Intelligent Network Simulation Model (INSIM) was employed for simulating a medium-sized area in Singapore. The results from experiments illustrated the influence of traffic information on mode choice. The results can provide foundations that can help the operations of a multimodal transportation system to regulate the travel demand based on the provision of multimodal real-time traveller information. Future study may be required to address the limitations of the system, e.g. considering more influence factors that will affect commuter's mode choice decisions, incorporating the mode choice and route choice rules at the same time.

\section{ACKNOWLEDGEMENT}

This work was conducted under the PhD research programme of the second author ( $\mathrm{Dr}$ Memon AA) in Nanyang Technological University. This work was financially supported by the Singapore National Research Foundation under its Campus for Research Excellence and Technological Enterprise (CREATE) programme.

\author{
孟梦 1,2 \\ mengm@ntu.edu.sg \\ A. A. MEMON ${ }^{3}$ \\ ab_ahad@eim.ae \\ 黄育兆 ${ }^{2}$ \\ cydwong@ntu.edu.sg \\ 林瑞海 ${ }^{4}$ \\ soihoi.lam@gmail.com \\ ${ }^{1}$ TUM CREATE, 新加坡138602, 新加坡 \\ 2 基建系统中心, 土木与环境工程学院, 南洋理工大学, \\ 新加坡639798, 新加坡 \\ ${ }^{3}$ IVES，迪拜，阿拉伯联合酋长国 \\ 4 运输基建办公室，澳门特别行政区 999078, 中国
}

\section{摘要}

综合交通信息对通勤者出行方式选择的动态影响研 究

综合交通信息条件下通勤者的出行方式选择直接依赖 于可利用的交通方式, 交通网络性能与控制策略以及交通 信息。本文利用自主研发的交通仿真模型INSIM, 针对新 加坡实际中型路网, 探究多方式网络中不同场景下交通信 息对通勤者的出行方式选择的影响。仿真结果显示：小汽 车出行向公共交通出行的转移与综合交通信息传播的数量 和信息更新的及时性有直接关系。其他影响因素包括交通 方式的可达性，交通信息服从度以及交通事故等引起的交 通拥挤。

\section{关键字}

综合交通信息；出行方式选择；交通仿真，转移倾向 


\section{REFERENCES}

[1] Bekhor S, Dobler C, Axhausen KW. Integration of activity-based and agent-based models. Transportation Research Record: Journal of the Transportation Research Board. 2011;2255:38-47.

[2] Kenyon S, Lyons G. The value of integrated multimodal traveller information and its potential contribution to modal change. Transportation Research Part F: Traffic Psychology and Behaviour. 2003;6(1):1-21.

[3] Märki F, Charypar D, Axhausen KW. Continuous activity planning for continuous traffic simulation. Transportation Research Record: Journal of the Transportation Research Board. 2011;2230:29-37.

[4] Wang W, Zhang W, Guo H, Bubb H, Ikeuchi K. A safety-based approaching behavioural model with various driving characteristics. Transportation Research Part C. 2011;19(6):1202-1214.

[5] Dia H. An agent-based approach to modelling driver route choice behaviour under the influence of real-time information. Transportation Research Part C. 2002;10(5):331-349.

[6] Kenyon S, Lyons G. The value of integrated multimodal traveller information and its potential contribution to modal change. Transportation Research Part F. 2003;6(1):1-21.

[7] Ben-Elia E, Shiftan Y. Which road do I take? A learning-based model of route-choice behavior with real-time information. Transportation Research Part A. 2010;44(4):249-264.

[8] Chorus CG, Molin EJE, Van Wee B. Use and effects of Advanced Traveller Information Services (ATIS): a review of the literature. Transport Reviews. 2006;26(2):127-149.

[9] Van Aerde M, Hellinga B, Baker M, Rakha H. INTEGRATION: An overview of traffic simulation features. Presented at $75^{\text {th }}$ Annual Meeting of the Transportation Research Board. Washington DC; 1996.
[10] Wang PT, Glassco RA. Enhanced THOREAU traffic simulation for intelligent transportation systems (ITS). In: Proceedings of the $27^{\text {th }}$ Conference on Winter Simulation. IEEE Computer Society, 1995; p. 1110-1115.

[11] Jayakrishnan R, Oh JS, Sahraoui AEK. Calibration and path dynamics issues in microscopic simulation for advanced traffic management and information systems. Transportation Research Record: Journal of the Transportation Research Board. 2001;1771(1):9-17.

[12] Barceló J, Ferrer JL, Grau R. A route based variant of the AIMSUN2 microsimulation model. Proceedings of the Steps Forward - Intelligent Transport Systems World Congress, Volume 4; 1995 Nov 9-11; Yokohama, Japan; 1995.

[13] Cameron GD, Duncan GI. PARAMICS - Parallel microscopic simulation of road traffic. The Journal of Supercomputing. 1996;10(1):25-53.

[14] Nakajima Y, Yamane S, Hattori H. Multi-model based simulation platform for urban traffic simulation. Principles and Practice of Multi-Agent Systems. Springer Berlin Heidelberg, 2012; p. 228-241.

[15] Meng M, Shao CF, Zeng JJ, Dong CJ. A simulation-based dynamic traffic assignment model with combined modes. PROMET - Traffic \& Transportation. 2014;26(1):65-73.

[16] Memon AA, Meng M, Wong YD, Lam SH. Rulebased mode choice model - INSIM expert system. Journal of Transportation Engineering - ASCE. 2015;141(4):04014088.

[17] Lam SH, Memon AA. Development of an intelligent traffic simulation model (INSIM) for evaluating the effects of multi-modal traveller information. Publication of: ARRB Transport Research, Limited; 2003. 